\title{
Educação escolar e cultura corporal em áreas de reforma agrária: a emancipação humana em análise
}

CDD. 20.ed. 306

379.81

http://dx.doi.org/10.1590/1807-55092016000401079
Tiago Nicola LAVOURA*
*Departamento de Ciências da Saúde, Universidade Estadual de Santa Cruz, llhéus, BA, Brasil.

\section{Resumo}

0 presente artigo teve o objetivo de apreender os fundamentos pedagógicos do ensino da cultura corporal na educação escolar do Movimento dos Trabalhadores Rurais Sem Terra - MST. A luz do materialismo histórico-dialético, os dados empíricos da pesquisa apontam a pedagogia dos projetos fundamentando o trabalho educativo do MST no assentamento investigado. Ao entendermos que o MST deve ter acesso ao conhecimento na sua forma mais desenvolvida, na medida em que o mesmo se torna parte constitutiva do instrumental de luta do Movimento e da classe trabalhadora, defende-se a necessidade de seu trabalho educativo estar fundamentado na pedagogia histórico-crítica, como forma de se possibilitar a formação plena de conteúdos em cada indivíduo singular.

PalavRas-chave: Educação escolar; Cultura corporal; Pedagogia histórico-critica; Emancipação humana.

\section{Introdução}

Reconhecemos o MST como o movimento de organização social popular que historicamente mais tem expressado a luta da classe trabalhadora do campo contra o capitalismo, se confrontando com um dos seus pilares fundamentais, a propriedade privada da terra e dos meios de produção.

Assertivamente, seus processos de organizaçáo e produçáo nos assentamentos, bem como, sua luta por uma educaçáo que se pretende emancipadora, deve estar atrelada ao acesso ao conhecimento científico, artístico e filosófico e, ainda, à busca por um tempo livre e de lazer no qual se almeje um tempo para o gozo de uma atividade livre, universal e criativa e que permita o usufruto da arte, da literatura, da música, do jogo e do esporte, da dança, da ginástica, enfim, de tudo aquilo que chamamos de cultura, mesmo que ainda na complexa e contraditória totalidade das relaçóes sociais do modo de produção capitalista.

Isto porque o acesso ao patrimônio imaterial já construído historicamente e acumulado socialmente pela humanidade é fundamental para o processo de formação humana de cada indivíduo singular, conforme aponta DUARTE ${ }^{1}$. Neste sentido, a classe trabalhadora - nela incluída os trabalhadores do campo e os integrantes do MST - deve lutar por condiçôes de usufruto deste conjunto de atividades as quais são produçôes da humanidade, incluídos os conteúdos da cultura corporal os quais se materializam nas diferentes formas de jogos, de esporte, de lutas, de ginástica, de dança, de formas de exercitar e conhecer o corpo, enfim, diferentes formas de objetivação da corporalidade determinadas em última instância pela necessidade de existência dos homens.

O objeto de estudo do presente trabalho foi a cultura corporal e a educação escolar na prática social do MST, analisado a partir dos fundamentos da pedagogia histórico-crítica. Tendo como ponto de partida o seguinte problema investigativo: quais os conteúdos e os fundamentos da cultura corporal presentes na educação escolar do MST, suas possibilidades formativas e perspectivas emancipatórias? Entendemos que tal objeto e problemática possuem extrema relevância, visto que o trabalho educativo e, em seu âmbito, o ensino dos conteúdos da cultura corporal, incidem na formação humana e na prática social destes indivíduos, em seus processos organizativos de luta e de confrontaçáo ao modo do capital organizar a vida.

Vale deixar claro que artigo é fruto de uma pesquisa de doutorado e teve como objetivo principal apreender os fundamentos pedagógicos do ensino da cultura corporal na educação escolar do Movimento dos Trabalhadores Rurais Sem Terra - MST. 
Há que se salientar que os movimentos populares de luta social contra a exploração capitalista, dentre eles o MST, náo estáo isolados e imunes ao modo do capital organizar a vida. Muito pelo contrário, estão imersos e mergulhados nas contradiçôes da realidade social postas pela ordem burguesa.

Com efeito, a formação humana - de cada indivíduo singular - vem se efetivando nas complexas relações alienantes e alienadoras do modo de produção capitalista e, desta forma, os processos de humanização e alienação dos indivíduos estão em confronto ${ }^{2}$.

Desta feita, entendemos que as atividades formativas da cultura corporal no tempo livre e na educação escolar do MST devem ser permanentemente revisitadas e questionadas - sobretudo pelo próprio Movimento - como forma de se manter acesa a luta pela emancipação humana na perspectiva da superação revolucionária do modo de produção capitalista.

Esta pesquisa trata de uma contribuição ao debate sobre as alternativas revolucionárias a ordem burguesa, bem como, a necessidade de análise crítica dos projetos políticos pedagógicos da educação e da cultura corporal do MST os quais se propóe a contribuir para

\section{Método}

O método investigativo aqui percorrido está pautado no materialismo histórico-dialético, sendo que quatro momentos se espiralaram e se entrecruzaram para a realização da pesquisa, os quais podem ser caracterizados como os instrumentos de pensamento e de pesquisa: dados de conjuntura e estrutura; pesquisa bibliográfica, análise documental e entrevistas estruturadas 5 .

O estudo atendeu as recomendaçôes da Resolução n. 196/96 do Conselho Nacional de Saúde para estudos com seres humanos. Todos os participantes assinaram o Termo de Consentimento Livre e Esclarecido, sendo o estudo aprovado pelo Comitê de Ética em Pesquisa da Universidade Estadual de Santa Cruz e registrado na forma de parecer consubstanciado de n. 625.

O conteúdo das fontes foi analisado por meio de análise de conteúdo temático ${ }^{6}$, não obstante, sem a perspectiva do isolamento ou fragmentação de seus objetos de análise. Portanto, esta foi uma opção de natureza metodológica e didático-expositiva sem, no entanto, abandonar o sentido da unidade da totalidade.

A análise de conteúdo realizada no Programa de Ensino do componente curricular Educação Física a transformação social, mas, que em suas formulaçôes teórico-metodológicas podem acabar se articulando às concepçôes hegemônicas do campo educacional.

Dermeval SAVIANI ${ }^{3-4}$, desde o início da formulação de seus trabalhos de sistematizaçáo da pedagogia histórico-crítica, procurou partir do pressuposto fundamental de que é papel da escola a transmissão e apropriação, pelos filhos da classe trabalhadora, da riqueza cultural e intelectual da humanidade construída socialmente e acumulada historicamente, expressando a luta pelo socialismo em termos educacionais, correspondendo à luta pela socialização do conhecimento científico, artístico e filosófico nas suas formas mais desenvolvidas.

Finalizamos este processo investigativo defendendo a necessidade de construçáo de um trabalho pedagógico em âmbito escolar no MST o qual esteja fundamentado em uma teoria pedagógica que, de fato, contribua para a luta pela socialização do conhecimento científico, artístico e filosófico - incluído o trato com o conhecimento da cultura corporal - e que este conjunto de saber sistematizado possa interferir na prática social mais ampla destes indivíduos.

do Centro Estadual de Educação Profissional do Campo Milton Santos (CEEP), bem como, na transcrição das entrevistas estruturadas realizadas com uma professora de Educação Física desta escola do assentamento permitiram expor dados empíricos sobre a apropriação da cultura corporal e suas possibilidades formativas, na perspectiva da emancipação humana e superaçáo da sociedade de classes.

A análise dos fundamentos pedagógicos da cultura corporal no trabalho educativo escolar do Assentamento Terra Vista do Movimento dos Trabalhadores Rurais Sem Terra - MST, evidenciando suas possibilidades formativas e perspectivas emancipatórias, teve como referência a pedagogia histórico-crítica, notadamente uma teoria pedagógica inspirada pelos clássicos do marxismo e que, no debate contemporâneo das teorias pedagógicas, vem explicitando a defesa da educação escolar e da socialização do conhecimento - o saber sistematizado.

$\mathrm{O}$ assentamento Terra Vista foi conquistado por intermédio da luta de 350 famílias as quais ocuparam a até entâo fazenda de 904 hectares de terra existente nos arredores do município de Arataca, região Sul da Bahia. 
O assentamento obteve sua emissão de posse das terras em 1994, tendo hoje a presença de 55 famílias assentadas. Constituído por uma agrovila com 56 casas, sendo elas constituídas de dois ou três quartos, sala, cozinha e quintal produtivo, sua organização é viabilizada pela associação dos assentados e pelas setoriais de organização do assentamento como um todo, como setor de educação, de cultura, de saúde, de esporte, de produção, de juventude etc.

O Centro Estadual de Educação Profissional (CEEP) do Campo Milton Santos promove cinco cursos técnicos de nível médio (Agroecologia, Agroindústria, Meio
Ambiente, Zootecnia e Informática) e em um curso de qualificação profissional em Agroextrativismo para os alunos do $5^{\circ}$ ao $9^{\circ}$ ano do ensino fundamental.

O CEEP Milton Santos foi o primeiro centro temático do campo criado no Estado. Atualmente, tem 642 alunos matriculados. Aberto em 2011, foi criado pela Secretaria da Educação do Estado da Bahia em substituição ao Colégio Milton Santos, fundado em 2009. Os alunos são oriundos dos assentamentos Terra Vista e Aliança, bem como, alunos das cidades de Arataca, Juçari, Anori, Pau Brasil, Camacan, Mascote e Una.

\section{Resultados e discussão}

No CEEP Milton Santos, os alunos do fundamental de $5^{\circ}$ ao $9^{\circ}$ ano estudam no período noturno e náo existe o componente curricular Educação Física neste turno no Centro. Já os alunos dos cursos profissionais com médio integrado possuem aulas de Educação Física, porém, apenas no $1^{\circ}$ ano. No demais anos, este componente curricular não integra o quadro curricular dos cursos de formação profissional.

A cultura corporal é tema de objeto de estudo no CEEP Milton Santos nos cursos de formação profissional em Informática, Meio Ambiente, Agroecologia e Zootecnica, sendo que somente para os alunos do $1^{\circ}$ ano destes cursos o componente curricular Educação Física está presente na grade curricular.

Já de início, portanto, é possível fazer a constatação de algo muito comum e não exclusivo das escolas do campo acerca da Educação Física: uma constante redução - e no limite, a retirada - desta disciplina curricular das escolas públicas municipais e estaduais, privando os alunos do acesso ao conhecimento da cultura corporal produzida pelos homens ao longo da história da humanidade.

Importante destacar o fato de que o componente curricular Educação Física nesta escola do assentamento está sendo desenvolvido nestes cursos de educação profissional e, segundo a professora desta disciplina, isto, de certa forma, trás implicaçóes para a organização do trabalho pedagógico, visto que é necessário adequar os conteúdos da disciplina aos cursos técnicos em questão (Informática, Meio Ambiente, Agroecologia e Zootecnica).

O Plano de Educação Profissional da Bahia passou a ser implementado a partir da criação da Superintendência de Educação Profissional - Suprof, criada pelo Decreto Lei n. 10.955, de 21 de dezembro de
2007. É a Suprof a responsável por enviar os Planos de Curso de todos os cursos de educação profissional do governo estadual, os quais devem ser recebidos, adaptados e implementados pelos Centros de Educação Profissional, conforme necessidades, demandas e características de cada território ou região.

É desta maneira que o CEEP Milton Santos recebe os Planos de Curso dos cursos de educação profissional os quais são promovidos no Centro. No que diz respeito ao componente curricular Educação Física, a única referência feita pela Suprof é a de que se possibilite aos alunos a prática de atividades físicas e desportivas.

$\mathrm{Na}$ entrevista realizada com a única professora de Educação Física do CEEP Milton Santos, foi possível evidenciar que a mesma questiona este reducionismo da proposta curricular deste componente curricular nos cursos de formação profissional, fazendo alusão à dimensão cultural e histórica das práticas corporais no processo de formação humana, notadamente ao responder a pergunta "De maneira geral, de que forma você relaciona a disciplina Educação Física com a educaçâo e com a cultura, de maneira mais ampla?": Acredito que a Educação Física está constantemente ligada à educação e cultura pois as mesmas não andam distintas. Desde o início da história nas antigas civilizaçôes uma faz parte do processo contínuo de formação e contribuição do homem. Quando se estuda a história de um povo vários elementos são colocados em pauta: localizaçáo, linguagem, danças, comidas típicas, os costumes de uma forma geral. E tudo isso perpassa pelo processo de formação humana. Sendo assim a Educação Física está relacionada a todos os aspectos citados acima, mesmo que muitas vezes não são correlacionados 
pela população ao estudo da vivência corporal (Professora de Educaçáo Física do CEEPMS).

Quando perguntamos à professora sobre os objetivos com os quais ela trabalha o componente curricular Educação Física na escola, ela nos respondeu que seu objetivo é "proporcionar aos alunos a vivência, discutir e aprender conteúdos especificos do curso de referência". Notamos que a mesma faz um esforço em contextualizar determinados conteúdos da cultura corporal com o curso de formação profissional em que os alunos estão inseridos, conforme descrito nos programas de ensino de Educação Física nos diferentes cursos profissionais em que trabalha:

Conteúdos: Informática: tecnologia e seus reflexos na sociedade, cyberbullying, a tecnologia e o isolamento social; Meio Ambiente: a relação entre Educação Física e meio ambiente, caminhada orientada, saúde e qualidade de vida; Agroecologia: alimentação saudável, alimentos orgânicos e inorgânicos, caminhada orientada; Zootecnica: alimentação saudável, manipulação de alimentos e manipulação correta de animais.

Nos programas de ensino da Educação Física para estes cursos de formação profissional, não há nenhuma referência explícita sobre a teoria pedagógica a pautar o trabalho a ser desenvolvido, tampouco sobre a metodologia de ensino da Educação Física escolar adotada. $\mathrm{O}$ método de ensino assim está descrito nos documentos da professora: "Trabalhar teoria $e$ prática; projetos de intervenção e visita técnica".

Não obstante, pode-se notar certa ênfase na dimensão prática da formação dos alunos. Mesmo sem anunciar explicitamente, é possível fazer relação ao trabalho da professora com a pedagogia de projetos, uma pedagogia embrionária do construtivismo e integrante do quadro das pedagogias do "aprender a aprender”. Segundo a professora:

Procuro fazer projetos de intervenção com os alunos de diversos cursos para aplicar no Florestan, nas cidades circunvizinhas e na própria sala de aula com os seguintes temas: alimentação saudável, reciclagem, artesanato e produtos extrativistas e etc. Porém existe a possibilidade com o novo planejamento de açóes do MST Assentamento Terra Vista de um trabalho específico dentro do assentamento: ginástica laboral, horta, ervas medicinais em parceria com os alunos e outros profissionais da saúde (Professora de Educação Física do CEEPMS).

Os estudos acerca da pedagogia dos projetos realizados por DUARTE ${ }^{7-8}$ evidenciam que esta está pautada em uma metodologia de ensino construtivista, desenvolvida por Kilpatrick, notadamente um seguidor de Dewey nos Estados Unidos. Nesta pedagogia, as atividades escolares não são criadas em torno de um currículo previamente estabelecido e sistematizado decorrente da seleção e organização dos conteúdos clássicos de cada componente curricular, os quais devem ser transmitidos e assimilados pelos alunos.

Os projetos surgem espontaneamente nas discussóes entre alunos e professores, podendo ser inter ou multidisciplinares, com a justificativa de se tentar superar a fragmentação do conhecimento por intermédio da ênfase ao trato mais holístico do saber. Não obstante, o que ocorre com a pedagogia de projetos é que a mesma acaba por reduzir e, no limite, eliminar o currículo escolar e as disciplinas curriculares, minando a especificidade do trabalho educativo escolar e a tarefa do professor de transmissão do conhecimento elaborado ${ }^{7}$. Desta feita:

A ideia central do método de projetos é de que o conhecimento deve ser buscado pelos alunos a partir de necessidades de sua vida real, opondo-se aos currículos preestabelecidos nos quais o conhecimento é organizado numa sequência lógica e temporal. $\mathrm{O}$ pragmatismo de John Dewey é sem dúvida a base filosófica do método de projetos. Igualmente central no método de projetos é o desenvolvimento da atitude investigativa e do pensamento científico autônomo, considerados por Dewey e por Kilpatrick indispensáveis à cidadania na democracia liberal ${ }^{7}$ (p.41).

Segundo a professora, o fato de a Educação Física possibilitar o desenvolvimento de projetos de intervenção em determinados espaços e com as demais pessoas do assentamento, isto já faz com que haja um envolvimento deste componente curricular com o contexto mais geral das lutas e reivindicaçóes do MST. Não obstante, o que a pesquisa de campo aponta é uma lacuna quanto a dois elementos essenciais do trabalho educativo e da prática social no âmbito do MST: a) a relação dos conteúdos trabalhados em âmbito escolar na Educação Física com a prática social mais ampla dos indivíduos e; b) a contribuição dos conteúdos da cultura corporal para o projeto de emancipação humana do MST e da classe trabalhadora.

Quanto ao primeiro elemento, para a professora, o fato de a Educação Física possibilitar o desenvolvimento interpessoal por meio das aulas práticas com jogos lúdicos e esportivos, tais conteúdos passam a ser instrumento de sociabilização na vida dos indivíduos, segundo ela: 
[...] possibilitando assim a quebra de preconceitos e a convivência saudável. Há troca de experiências, sociabilização entre os pequenos centros e o assentamento, assim diretamente interferindo nas relaçóes interpessoais onde se trabalha muito nas aulas de Educação Física o respeito às diferenças (Professora de Educação Física do CEEPMS).

Em que pese que na escola e nas aulas de Educação Física existam momentos de sociabilização, convívio e interação, entendemos que não haja a necessidade da escola para que ocorram processos de socialização e interação entre os indivíduos, visto que a própria prática social possibilita isto. Nas esferas da vida cotidiana existem possibilidades de encontro, diálogo, interação e desenvolvimento interpessoal.

É evidente que isto também ocorre na educação escolar. Porém, entendemos que o trabalho educativo escolar não pode ficar reduzido a estes processos de sociabilização. Concordamos com a tese da pedagogia histórico-crítica ${ }^{3-4}$ de que tarefa da educação escolar é a de transmissão do conhecimento sistematizado, de forma a promover a genericidade humana em cada indivíduo singular. Mas, como já alertara o próprio professor Dermeval Saviani, há que se encontrar os meios adequados para esta tarefa, e isto implica, também, a escolha de uma determinada teoria da prática educativa a fim de subsidiar e fundamentar o trabalho pedagógico.

No que se refere ao segundo elemento - a contribuiçáo dos conteúdos da cultura corporal para o projeto de emancipação humana do MST e da classe trabalhadora - constata-se que a compreensão da categoria emancipação humana está pautada no senso comum, tampouco é corretamente compreendida na acepção marxiana de uma nova forma de sociabilidade - por meio da revolução proletária - na qual os homens sejam efetivamente livres, pressupondo, portanto, a erradicação do capital e suas formas alienantes e alienadoras de relaçóes sociais assentadas da propriedade privada e na divisão social do trabalho.

Ao perguntarmos de que maneira os conteúdos da cultura corporal trabalhados na disciplina Educação Física podem contribuir para o projeto de Emancipação Humana do MST, a professora respondeu que "muitos dos conteúdos trabalhados em nossa área contribuem de forma concreta em algumas propostas e objetivos a serem alcançados pelos assentados como: qualidade de vida em um âmbito geral".

O legado teórico marxista e o desenvolvimento da prática política no seio da própria sociedade capitalista possibilitam evidenciar que categorias como qualidade de vida, bem estar social, inovação e cidadania são representaçóes idealizadas as quais não tem força para superar a alienação das relaçóes sociais.

$\mathrm{MARX}^{9}$ assim se reporta à emancipação humana na Critica à filosofia do direito de Hegel:

O sonho utópico da Alemanha náo é a revolução radical, a emancipação humana universal, mas a revolução parcial, meramente política, que deixa de pé os pilares do edifício. Qual a base de uma revolução parcial, meramente política? Apenas esta: uma seçấo da sociedade civil emancipa-se e alcança o domínio universal: uma determinada classe empreende, a partir da sua situação particular, uma emancipação geral da situação. Tal classe emancipa a sociedade como um todo, mas só no caso de a totalidade da sociedade se encontrar na mesma situação que esta classe; por exemplo, se possuir ou facilmente puder adquirir dinheiro ou cultura (p.154).

Evidenciamos falta de aprofundamento teórico, sobretudo acerca de uma dada teoria do conhecimento a qual esteja vinculada às necessidades e anseios do MST e da classe trabalhadora, de maneira geral. Conforme aponta D'Agostini ${ }^{10}$, a secundarização da teoria e, notadamente, a fragilidade teórica acerca do materialismo histórico-dialético na educação do campo vem permitindo desvios da prática política e pedagógica, o que acarreta implicaçóes também na materialização da educação do MST e na sua consolidação como uma pedagogia de vertente marxista e socialista.

Diante de tais constataçóes, reafirmamos a necessidade de que o conhecimento - incluindo-se a cultura corporal - seja tratado na educação escolar do MST - e da classe trabalhadora em geral - estando pautado em pressupostos teórico-metodológicos os quais expressem:

[...] um conjunto de elementos que, articulados, ampliam nossas possibilidades de abordar a realidade no sentido de sua compreensão, da produção de conhecimentos, do encaminhamento de açôes, enfim, de entender, explicar e agir no enfrentamento dos problemas postos pela existência ${ }^{11}$ (p.38).

De igual maneira, apontamos a necessidade de uma teoria pedagógica a qual tenha inspiração no marxismo e, portanto, seja a expressão de uma concepçáo pedagógica atrelada à concepção de mundo e de homem própria do materialismo histórico-dialético. E, no que diz respeito à relação entre luta de classes e educação escolar, entendemos que a pedagogia histórico-crítica vem acumulando formulações teóricas e proposiçóes didático-metodológicas as quais podem contribuir para o avanço das lutas do Movimento como um todo, pois, conforme afirma SANTOS ${ }^{12}$ : 
[...] é do interesse dos trabalhadores compreender a realidade e desvelar os segredos das forças que os oprimem. Esse processo exige, além da luta política, o momento teórico que potencialize ao máximo a capacidade intelectual e organizativa desses indivíduos, o que se realiza por meio da educação. Nesse sentido é que se pode falar que é um dever dessa classe lutar pelo direito à educação em suas formas mais ricas em direção à superação das relaçôes sociais de dominação (p.195).

A pedagogia histórico-crítica não nega que a produção do conhecimento é e está na prática social, tampouco não deixa de reconhecer que existem espaços formativos os quais transcendem a educação escolar, como a família, o sindicato, o partido e o próprio movimento. Porém, ela reconhece e defende a especificidade da educação escolar, a qual se diferencia dos outros espaços formativos.

Aquilo que especificamente deve ser tratado na educação escolar, por excelência, não poderá ser desenvolvido em nenhum outro espaço formativo. Sua função de transmissão e assimilação do conhecimento sistematizado - acerca da ciência, da filosofia, da arte, da cultura corporal, dentre outros - com o intuito de fazer com que o aluno ultrapasse os níveis de conhecimento do senso comum para uma consciência filosófica ${ }^{13}$, ou seja, que o indivíduo transite das formas cotidianas de entendimento da realidade para as formas não-cotidianas ${ }^{1,14}$, faz com que ela - a educaçáo escolar - se insira na dinâmica e na luta de classes.

O MST deve ter acesso ao conhecimento elaborado na medida em que o mesmo se torna parte constitutiva do instrumental de luta do Movimento e da classe trabalhadora como um todo. Abrir mão da escola ou secundarizar sua importância não reconhecendo seu papel na formação plena dos indivíduos significa fazer "[...] coro com as propostas que visam abandonar as camadas populares a sua própria sorte em relação à formação teórico-científica, o que repercute em maiores dificuldades para a sua organização enquanto classe para si"12 (p.201). Nesse sentido:

[...] a pedagogia histórico-crítica tem dado sua contribuição específica considerando que, para o avanço da organização das camadas populares em direção à socialização das riquezas materiais e espirituais produzida pelo conjunto dos homens, a apropriação do conhecimento sistematizado é de extrema importância. Para isso desenvolve suas análises e proposiçóes pedagógicas articulando o trabalho educativo aos processos de lutas sociais gerais, reconhecendo na escola o lugar por excelência da luta pela socializaçáo do conhecimento (p.197).
Fica claro, portanto, que esta teoria pedagógica náo compreende a educação escolar e o conhecimento sistematizado como algo nocivo às camadas populares e suas organizaçóes, no sentido de conceber a transmissão deste conhecimento via escola uma invasão cultural e uma tentativa de dominação. Tampouco compreende que a defesa da escola e do cumprimento de sua função profícua seja uma perspectiva escolacentrista, cientificista ou um cognitivismo conteudista, conforme defende Arroyo ${ }^{15}$ embevecido da pedagogia multiculturalista e do pós-modernismo:

Os movimentos nos pressionam para reconhecer que a cultura é um componente central da formação, da compreensão dos processos sociais e educativos. Centralidade esquecida no cientificismo e cognitivismo conteudista de nossa tradição escolar que invade e contamina até as experiências de educação não formal [...] [e] se deixam apressadamente influenciar por velhos olhares escolacentristas. Em vez de enfatizar a educação como ação cultural e em vez de pensar na cultura vivida e devida aderimos a visóes cientificistas e instrumentalistas de conhecimento até na educação não-formal. [...] Estou sugerindo que os movimentos nos puxam para o campo da cultura: mais aberto do que as opçóes estreitas de conhecimento instrumental e de competências úteis que tanto limitaram nosso olhar e pensar pedagógico. [...] A cultura do povo, dos jovens e adultos, das comunidades negras, dos povos indígenas, ainda é vista pela cultura escolar como primitivismo, preconceito, crenças a serem superadas pelo saber racional instrumental moderno. Uma visão reducionista da cultura como emanando do agir humano mais tradicional e estático. Uma visão de cultura que contaminou a visão do povo (p.40).

Debater aprofundadamente questôes que entendemos problemáticas da pedagogia multiculturalista não nos é possível neste momento, em virtude das limitaçóes deste artigo. Entretanto, vale ressaltar, conforme evidencia Della Fonte ${ }^{16}$ que:

O multiculturalismo crítico/ intercultural possui um discurso sedutor porque se constrói a partir de alguns traços que o colocam aparentemente no campo político das proposiçóes pedagógicas de esquerda. Sob a ótica do multiculturalismo crítico/intercultural, a ciência representa uma narrativa e necessita passar pela crítica cultural para evidenciar sua lógica ocidental, eurocêntrica, masculina, moderna e sua pretensão de verdade. Isso só poderia ocorrer na intersecção e no atrito com outras narrativas que foram silenciadas ao 
longo da história. Dessa tensão, novos saberes híbridos poderiam ser gerados e a escola, então, cumpriria um papel de fomentar as interaçóes culturais a partir da garantia da igualdade das narrativas plurais e da afirmação das diferenças na construção do igualitarismo. Logo, a presença de outras narrativas culturais que desconstruam a monocultura, por exemplo, enriqueceria a possibilidade de crítica cultural e de descolonização do currículo escolar. [...] O multiculturalismo crítico é uma proposição teórica cujos fundamentos ultrapassam a mera defesa da diversidade cultural (aspecto também defendido por outras vertentes). O seu núcleo central encontra-se em defender a diversidade por meio do relativismo ontológico e o ceticismo epistemológico (p.2).

Ao conceber o trabalho educativo como o ato de se produzir a humanidade em cada indivíduo singular, a pedagogia histórico-crítica ${ }^{3-4}$ está se pautando na análise marxiana sobre a dialética da apropriação e objetivação do gênero humano, a qual traduz a reciprocidade entre o universal (o gênero) e o singular (o indivíduo) por intermédio da mediaçáo particular do trabalho educativo. Neste sentido, o homem é concebido como síntese de múltiplas relaçôes, unidade da diversidade, e não um ser abstrato portador de uma essência universal a ser alcançada por intermédio do trabalho educativo - como postulava a pedagogia tradicional.

Neste sentido é que a escola é compreendida como "[...] lócus de encontro entre a singularidade existencial e a universalidade do gênero humano. $\mathrm{O}$ trabalho escolar pode contribuir para que cada ser humano converta as aquisiçóes do conjunto da humanidade em capacidades próprias, órgáos de sua individualidade"16. (p.11, destaque da autora), expressáo utilizada por Marx nos manuscritos de 1844.

Ao defender o acesso às formas elaboradas do conhecimento, necessariamente envolvendo o distanciamento dos indivíduos do seu viver cotidiano, não se está defendendo a inculcação - via transmissão escolar - de uma cultura homogeneizada a qual não reconheça a singularidade dos indivíduos. Não se trata disso.

Se trata de reconhecer a escola em sua função mediadora entre o conhecimento espontâneo e as formas culturais elaboradas, função esta que é uma exigência para que os indivíduos - inclusive os povos do campo - possam ir em busca de uma humanidade a qual vem sendo produzida historicamente.

Numa sociedade pautada na propriedade privada dos meios de produção e na divisão de classes antagônicas, ocorre é que suas relaçôes alienantes e alienadoras promovem possibilidades desiguais dos indivíduos saírem em busca desta humanidade. Neste sentido, as diferenças são firmadas e ofuscadas por meio da desigualdade entre as classes. Somente em uma sociedade de iguais é que as diferenças poderão, de fato, se manifestar.

Tal feito implica, evidentemente, a superação das formas alienadas de trabalho humano e de relaçóes sociais de produção impostas pelo modo de produção capitalista. A escola, por si só, não possibilitará tal feito. Mas, sem ela e a efetivação de sua função mediadora na prática social mais ampla, tornar-se-á evidente as limitaçóes da atuação dos indivíduos na medida em que os mesmos tenderão a estar alijados do desenvolvimento de suas máximas capacidades humanas.

Desta feita, a pedagogia histórico-crítica tem procurado respaldar o trabalho educativo escolar para que o mesmo mobilize os saberes populares e determinadas atividades da esfera da vida cotidiana para o universo das formas culturais mais elaboradas da ciência, da arte, da filosofia e da política, desejando que "[...] o aluno possa se relacionar conscientemente com esse cotidiano, mediado pela apropriação dos conhecimentos científicos, artísticos, ético-filosóficos e políticos”, conforme afirmação de $\operatorname{DuArte}^{1}$ (p.58).

Ciente da necessidade de se debater mais amplamente e aprofundadamente o objeto de estudo em questão, esperamos que este artigo tenha conseguido apontar algumas contradiçóes e possibilidades de superação da educação escolar e da cultura corporal na prática social do MST, notadamente ao apontar a importância do trabalho educativo do MST em priorizar a apropriação, de cada aluno singular, dos conhecimentos necessários ao seu pleno desenvolvimento como seres humanos, ainda nos estreitos limites da sociedade capitalista, o que implica no caso da Educação Física, o ensino intencional e sistematizado dos conteúdos da cultura corporal historicamente acumulados e que se constituem enquanto patrimônio cultural humano, devendo os mesmos, portanto, serem socializados por intermédio do ensino escolar. 


\section{Abstract}

School education and culture corporal in areas of agrarian reform: a human emancipation in analysis

This article aimed at learning the pedagogical fundamentals of teaching the culture corporal in school education of the Landless Rural Workers Movement - MST. The light of historical and dialectical materialism, the empirical research indicate pedagogy projects basing the educational work of the MST settlement investigated. When we understand that the MST should have access to knowledge in its most developed form, in that it becomes a constitutive part of the instrumental movement's struggle and the working class, defends the need for their educational work is grounded in pedagogy historical-critical as a way to enable the formation of full content in each single individual.

KEY WoRDS: School education; Culture corporal; Historical-critical pedagogy; Human emancipation.

\section{Referências}

1. Duarte N. Educação escolar, teoria do cotidiano e a escola de Vigotski. 4a ed. Campinas: Autores Associados; 2007.

2. Duarte N. A individualidade para-si: contribuição a uma teoria histórico-social da formação do indivíduo. Campinas: Autores Associados; 1993.

3. Saviani D. Pedagogia histórico-crítica: primeiras aproximaçóes. 10a ed. São Paulo: Autores Associados; 2008.

4. Saviani D. Escola e democracia. 41a ed. São Paulo: Autores Associados; 2009.

5. Gil AC. Métodos e técnicas de pesquisa social. 5a ed. São Paulo: Atlas; 1999.

6. Richardson RJ. Pesquisa social: métodos e técnicas. São Paulo: Atlas; 1999.

7. Duarte N. O debate contemporâneo das teorias pedagógicas. In: Martins LM, Duarte N, organizadores. Formação de professores: limites contemporâneos e alternativas necessárias. São Paulo: Cultura Acadêmica; 2010. p.33-50.

8. Duarte N. As pedagogias do "aprender a aprender" e algumas ilusóes da assim chamada sociedade do conhecimento. Rev Bras Ed. 2001;18:35-41.

9. Marx K. Crítica da filosofia do direito de Hegel. São Paulo: Boitempo; 2005.

10. D’Agostini A. A educação do MST no contexto educacional brasileiro [tese]. Salvador (BA): Universidade Federal da Bahia, Faculdade de Educação; 2009.

11. Santos Júnior CL, Lima JF, Santana FS, et al. Mutirôes e círculos de esporte e lazer: bases teórico-metodológicas do projeto de ensino e investigação. In: Colavolpe CR., Taffarel CNZ, Santos Júnior CL, organizadores. Trabalho pedagógico e formação de professores/militantes culturais: construindo políticas públicas para a educação física, esporte e lazer. Salvador: EDUFBA; 2009. p.27-32.

12. Santos, CF. Pedagogia histórico-crítica e movimentos sociais populares: para além das dicotomias entre práticas educativas escolares e não escolares. In: Marsiglia ACG, Batista EL, organizadores. Pedagogia histórico-crítica: desafios e perspectivas para uma educação transformadora. Campinas: Autores Associados; 2012. p.181-206.

13. Saviani D. Educação: do senso comum à consciência filosófica. 10a ed. São Paulo: Cortez/Autores Associados; 1991. 14. Heller A. O cotidiano e a história. 8a ed. São Paulo: Paz e Terra; 2008.

15. Arroyo MG. Pedagogias em movimento: o que temos a aprender dos movimentos sociais? Currículo Front. 2003;3;1:28-49.

16. Della Fonte SS. Os desafios da diferença e da diversidade na educaçáo escolar: curso de formaçáo continuada. Vitória: Centro de Educação; 2011. [versão não publicada].

ENDEREÇO

Tiago Nicola Lavoura Departamento de Ciências da Saúde Universidade Estadual de Santa Cruz Rod. Ilhéus-Itabuna km 16 45662-0oo - Ilhéus - BA - BRASIL e-mail: nicolalavoura@uol.com.br
Recebido para publicação: 09/10/2013

1a. Revisão: 22/07/2014

2a. Revisão: 23/07/2014

Aceito: 21/07/2015 